IOS Press

\title{
Education in official statistics: A common challenge of providers of official statistics and universities
}

\author{
Elwira Navarre ${ }^{\mathrm{a}}$, Heli Lehtimäki ${ }^{\mathrm{a}}$, Markus Zwick ${ }^{\mathrm{b}}$ and Mojca Bavdažc,* \\ ${ }^{a}$ Eurostat, Unit A5 Methodology, Innovation in Official Statistics, Luxembourg \\ ${ }^{\mathrm{b}}$ DESTATIS, Wiesbaden, Germany \\ ${ }^{\mathrm{c}}$ School of Economics and Business, University of Ljubljana, Ljubljana, Slovenia
}

\begin{abstract}
In the fast-changing environment, the amount of available data is exploding and transforming it quickly into actionable information is not easy. Thus, reliable and comparable statistics are in increasingly high demand by the public, even more so in troubled times such as financial crisis and pandemics. However, crisis is also an exciting opportunity to tap into the interest of young people and harness their talent for working with official statistics.

Two initiatives at the European level are already in place to advance education in official statistics. As production environment started to change with increasingly rapid evolution of technologies and new data sources, Eurostat together with the European Statistical System (ESS) brought to life European Statistical Training Programme (ESTP) and European Master in Official Statistics (EMOS).

This papers briefly describes the origin and the main characteristics of both models of training, the bridges that they build, and discusses the way ahead.
\end{abstract}

Keywords: Training, partnership, stakeholders, skills, knowledge, courses, literacy

The CFO asks the CEO, "What happens if we invest in developing our people and they leave us?"

The CEO responds, "What happens if we don't, and they stay?

Trish Bertuzzi, The Sales Development Playbook: Build Repeatable Pipeline and Accelerate Growth with Inside Sales

\section{Introduction}

People are nowadays considered among the most crucial resources of any organisation, albeit of intangible nature. According to Becker [1], human capital represents knowledge, skills, health, and values embod-

\footnotetext{
*Corresponding author: Mojca Bavdaž, School of Economics and Business, University of Ljubljana, Kardeljeva pl. 17, SI - 1000 Ljubljana, Slovenia. Tel.: +386 15892630; Fax: +386 15892698; E-mail: mojca.bavdaz@ef.uni-lj.si.
}

ied in an individual. In short, it consists of sets or bundles of KSAOs (knowledge, skills, abilities and other characteristics) and can be general, thus valuable across organisations, or organisation-specific [2]. Human resources are also explicitly mentioned in Principle $3 \mathrm{Ad}$ equacy of Resources of the European Statistics Code of Practice $[3]^{1}$ besides financial and technical resources. These resources should be adequate both in magnitude and quality to meet statistical needs. It has never been easy to attract people to jobs in official statistics because statistics in general is not among the most popular subjects and because it has always been difficult to compete with compensation schemes in the private sector. The situation seems to have worsened recently as the private sector recognised the data-related compe-

\footnotetext{
${ }^{1}$ European Statistics Code of Practice (CoP) is a self-regulatory instrument adhered to in the European Statistical System (ESS). It sets the standard for developing, producing and disseminating European statistics.
} 
tencies as a possible source of competitive advantage. More than two decades ago, a McKinsey Report [4] coined the expression "war for talent". This "talent" has become scarcer in many parts of the world because of demographic trends of ageing population and ageing workforce. To official statistics, the information age brought new technology, new data sources and more computing power, which require new types of KSAOs. In principle, official statistics can get these KSAOs both by training their existing workforce and by attracting people that already possess them.

Two initiatives at the European level are already in place to advance education in official statistics. Eurostat together with the European Statistical System (ESS) brought to life European Statistical Training Programme (ESTP) and European Master in Official Statistics (EMOS). Both activities were recommended since a longer period $[5,6]$. This paper briefly describes the origin and the main characteristics of both models of training, analyses underlying partnerships, and discusses the two models in the context of current trends in human resource management and higher education. The paper concludes with recommendations for future actions.

\section{European Statistical Training Programme (ESTP)}

Dating back from 1990, Eurostat has invested in specialised statistical training courses, which today are delivered under the umbrella of ESTP. Imparted in the training sites of the EU and EFTA countries as well as the Eurostat premises in Luxembourg, the courses evolve in line with the learning needs identified within the ESS. Currently, the programme delivers annually some 50-60 training courses to help train around 1000 professionals per year, primarily targeting staff working in the National Statistical Authorities of the EU member states, EFTA and candidate countries, including to some extent - Eurostat staff.

While the main objective of the programme is to enhance the professional qualifications of European statisticians with continuous training in new methods, techniques and best practices, ESTP complements national training schemes. Since its inception, the offer has developed from courses under methodology, quality, dissemination, business, economic and social statistics, also tapping the gap of new emerging statistical needs such as new data sources, programming languages and communication. The integration and application of harmonised European concepts and definitions play a vi- tal role in the programme's development and aim at meeting the challenges of comparable statistics at the European and international level.

Through a balanced combination of theory and practice and a variety of didactical approaches, such as workshops, group discussions, lectures and exercises, the training intends to provide adequate solutions, including, in some cases, the simulation of real work situations. By providing the possibility to take part in European and international training courses at postgraduate level, the ESTP enhances the vocational training of European statisticians and connects counterparts and experts at national level with each other.

\subsection{Training needs and benefits}

To ensure that the training offer is constantly developed and adapted to changes in the work environment, and that it addresses skills needed in the future, the annual programme's preparatory process involves Eurostat units' feedback on new and current needs resulting from their Working Groups, Task Forces and Member States' requests, or evolution in their statistical or methodological domains. In parallel, a consultation asking for learning needs directly in the ESS member states is launched among the ESTP National Contact Points (NCPs). Finally, part of each course is an assessment relying on direct feedback by the participants, yielding in general high satisfaction rates. A joint assessment of the mentioned elements serves as a basis for establishing the annual ESTP programme. Such training needs analysis conducted at regular intervals and with direct involvement of all the ESS counterparts, not only does help identify any present knowledge gaps but also points out towards the direction of new emerging skills and advances at national levels, which can then be recaptured through new training courses designed at the ESTP level.

An invaluable aspect of the ESTP is the human element that allows seizing multiple opportunities offered by its richness. The diversity of the ESTP target audience allows statistical experts from various countries to come together, get to know each other, share their national work experience and exchange best professional practice. Moreover, trainers delivering courses under ESTP are predominantly professionals originating from the EU and EFTA National Statistical Authorities (acting as partners in consortium or subcontractors to contractors organising the outsourced ESTP courses) or Eurostat colleagues. Such teaching landscape, enhanced by individual lecturers coming from the aca- 
demic world, grants access to the latest developments and expertise in the field, and creates alignments across the various European stakeholders.

\subsection{Challenges}

The positive recognition of ESTP by the ESS community encounters some obstacles when it comes to outreach. Despite the fact that participation is free of charge, resource constraints of ESS members often relegate training to a secondary priority, making it difficult for staff members to physically attend courses organised in various European locations. For EMOS students offered a place in any of the ESTP classroom courses, that aspect seems often even more challenging. Another stumbling block might be the relatively limited number of places available in the ESTP courses, designed to ensure a high level of learner's interactivity and practically oriented training. Finally, based on the course level, the ESTP applicants are often expected to possess homogenous background knowledge in order to follow a course. While that should not discourage EMOS students to apply to basic-level training courses, it might pose a challenge in case of more specialised ESTP courses.

When consulted on learning/training needs in connection with establishing the annual ESTP catalogue, more and more frequently national statistical institutes pointed out the absence of online material in the offer. To tackle that need, ESTP introduced online webinars and some e-learning material. The recent pandemic context expanded the online offer even more, nevertheless, a wider ESTP online course offer had a snowball effect on the interest and the number of ESS applications. The emergence of new training formats can help foster the exchange of best practices as well as knowledge transfer to participants coming from outside the ESS statistical producers. However, there is a clear need for new formal and informal learning structures and tools that will bridge the distance between and meet the changing needs of staff and students who wish to fulfil the workplace expectations of the future.

\section{European Master in Official Statistics (EMOS)}

$\mathrm{EMOS}^{2}$ is a shared initiative by Eurostat, the $\mathrm{ESS}^{3}$ and European System of Central Banks (ESCB) ${ }^{4}$ to

\footnotetext{
${ }^{2}$ EMOS homepage: https://ec.europa.eu/eurostat/cros/content/ emos_en.

${ }^{3}$ ESS: https://ec.europa.eu/eurostat/web/european-statisticalsystem/overview.

${ }^{4}$ ESCB: https://www.ecb.europa.eu/ecb/orga/escb/.
}

connect producers of official statistics and academia at the European level. Concretely, EMOS is a 4-year-label awarded by the European Statistical System Committee (ESSC) to Master programmes that fulfil the EMOS education requirements in the field of official statistics. To date, the EMOS network of 32 programmes in 18 countries builds on existing and nationally accredited Master programmes in line with the EMOS learning outcomes ${ }^{5}$ familiarising the graduates with the system of official statistics, production models, statistical methods and dissemination.

Established cooperation between the EMOS labelled programmes with the national statistical institute or another authority producing official statistics is key: compulsory master's thesis and internship in the field of official statistics in close cooperation with a producer of official statistics bridge the gap between the theory and practice.

\subsection{EMOS rationale}

In the wake of data revolution in the 2000 s, discussions about a common framework for training of "official statisticians" resulted in the Workshop on a European Master in Official Statistics in Southampton in 2010. The event gathered national statistical institutes and academia from over 20 European countries to discuss how to provide postgraduate training in official statistics and how to reinforce the collaboration between universities and producers of official statistics. Subsequently, a feasibility study in 2012 recommended building the EMOS label on already existing Master programmes. The aim was to:

- Ensure a wider offer of higher education in the area of official statistics in Europe and curricula adapted to the changing needs of statistical authorities.

- Meet training and recruitment needs by constituting a future recruitment pool of highly educated professionals for purposes of official statistics.

- Strengthen the cooperation between academia and the ESS, e.g. on research topics of relevance for official statistics.

- Reinforce the network of professional statisticians at international level.

- Develop a shared vision on methodology, organisation and management of the production of European statistics, by involving both academia and the ESS as teaching parties in EMOS.

\footnotetext{
${ }^{5}$ EMOS learning outcomes: https://ec.europa.eu/eurostat/cros/ content/learning-outcomes-emos-programmes_en.
} 

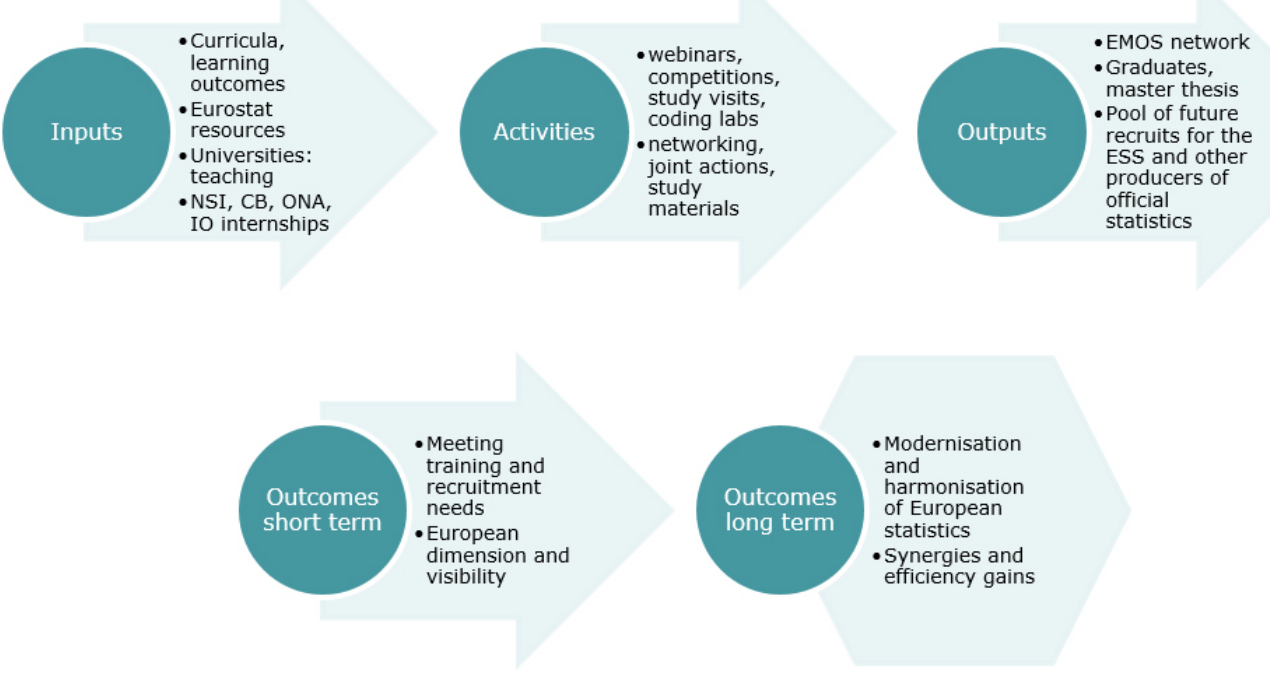

Fig. 1. EMOS intervention logic.

EMOS in the auspices of Eurostat got started in 2014. First three calls for applications aimed at creating a sizeable network, deemed sufficient with 32 programmes in 18 countries by 2021 (with reference to the feasibility study estimate of 25 programmes ready to quickly implement the EMOS concept). Since then a permanently open call with cut-off dates is open for those aspiring to obtain the EMOS label and focus have shifted into integration of activities and synergies in the network (see Fig. 1).

\subsection{Relevance}

EMOS learning outcomes focus on five main pillars to familiarise the graduates with the system of official statistics, production models, statistical methods and dissemination. The learning outcomes were crafted from the start to allow both for flexibility to cater for evolving training needs as well as for the stability required by the Master Programmes, bound to national accreditation requirements.

Thus, while disruptive changes to the learning outcomes are not advisable, it is yet necessary to update them within the existing margin. The learning outcomes were revised in 2019 to address the rapidly changing landscape from design-based production of official statistics to integrating different kinds of data sources, including unstructured (big) data. Students need a blend of different skills to cope with multisource statistics such as administrative data sources and big data, along with associated new statistical production methods that make more frequent use of model-based and algorithm- based estimation techniques. Moreover, future statisticians will need to be knowledgeable not just about technicalities but understand the institutional environment and dissemination aspects in their national contexts and at the European level. Also, communicating statistical products needs new type of storytelling, requiring strong communication capabilities and soft skills.

The relevance of EMOS learning outcomes and performance of the labelled programmes are monitored by the EMOS Board reporting to the ESSC for decision making. In addition, new learning needs are flexibly catered for with EMOS activities such as webinars, coding labs and study visits.

\subsection{Impact}

EMOS labelled programmes report annually to the EMOS Board about their performance and challenges. It is to be noted that the number of students following EMOS-labelled master programmes is not easy to determine as students can often freely customise their curriculum and their EMOS qualifications only become clear at the end of their studies. In the reporting period 2017-2020 EMOS programmes counted 359 EMOS graduates. According to a 2019 small graduate survey, roughly one third of 46 respondents were employed at the private sector and one quarter by the producers of official statistics. The reported job profiles of EMOS graduates included the following:

- Official statistics (national statistical institutes/ national central banks/other national authorities) 
jobs included data analysts, business controllers, IT programmers, web scrapers etc. in the areas of census, budget, agriculture, enterprise, air emissions, balance of payments, fraud/anomaly detection, indexes etc. For example, Destatis in Germany also includes EMOS label as "desirable" in their vacancy notices and encourages their staff members to take the degree, also outside Germany. Several EMOS graduates are employed in Destatis and in the statistical offices of the Länder.

- Private sector: job profiles mostly relate to data science: data analysts, data controllers, data science engineering, digital marketing, market and price analysis in the areas of e.g. the banking, retail, insurance, consulting and real estate sectors.

- Academia: research positions.

While no exact numbers are known, it is likely that some EMOS graduates also find employment among the users of official statistics.

Note that employment conditions are not known e.g. by type of contracts (permanent/temporary) and salary levels may vary a lot among the countries.

\subsection{Challenges}

Feedback by the universities, students and ESS/ESCB has identified the following challenges:

- Traineeship experience is valued by students and many would wish to carry out their traineeship outside their own country.

- More exchange opportunities among the EMOS programmes and enhancing networking among students within and beyond national programmes.

- Facilitating employment of graduates in the sphere of official statistics.

- More emphasis on data science aspects in study plans.

- Need for more commitment from the producers of official statistics.

While ongoing activities such as webinars, workshops and master's thesis competition continue, new activities have been developed: remote coding lab took place in summer 2020, new learning resources are being developed and a cross-border student mobility pilot programme is about to be launched.

\section{Bridges}

ESTP and EMOS share many characteristics as they both:

- aim to meet the training needs of the ESS;

- cover traditional and contemporary topics;
- involve experts from official statistics and academia;

- use the traditional educational setting;

- and reach a limited target audience.

At the same time, the two models of training also possess some different characteristics, which make them good complements to each other. Primarily, they target different audience (current vs. future staff), offer a different knowledge recognition (formal vs. non-formal) and require a different time investment (a typical twoyear cycle vs. 2-5 training days). Despite these differences, both models may be viewed as providing support for several bridges.

\subsection{Bridge across countries and cultures}

With an increasing number of international projects, working groups and other types of collaborations across national boundaries that official statisticians are involved in, their work is also becoming more global. Global work brings together people from different institutional environments, that experience cultural, linguistic, special and temporal distances [7]. These differences might play an important role, especially when they lead to different behaviour; they require confrontation and solutions [8]. Cultural intelligence, a person's "capacity to adapt to new cultural settings based on multiple facets including cognitive, motivational and behavioural features" [9, p. 271], should therefore be a valued characteristic that facilitates interactions among statisticians in international settings. Understanding cultural differences seems especially relevant when working on setting international standards, which is an ongoing endeavour in official statistics. Both ESTP and EMOS have an international component that can help develop intercultural competencies, value diversity and build a bridge across countries and cultures. Training courses conducted in the ESTP framework bring together people from different countries by default; EMOS strives to make this component more widely accessible by organising annual study visits to Eurostat for students from different EMOS programmes, stressing the importance of Erasmus mobility schemes and by supporting a student mobility pilot programme for cross-border internships.

\subsection{Bridge across generations}

As elsewhere in the world, also in official statistics very different generations work together, Baby Boomers (born 1946-1960), Gen Xers or Generation X (born 
1960-1980), and Millennials or Generation Y (born 1980-1995), with different work values, attitudes and career expectations [10]. Members of Generation Z (born up to 2005), the first generation of digital natives, are now in higher education and/or entering the labour market [11]. EMOS activities that bridge the worlds of official statistics and academia (see the next point), may therefore also be regarded as a bridge between generations, especially between Generation $\mathrm{Z}$ and other generations. EMOS core module on official statistics provides a common knowledge base needed to engage effectively in knowledge exchange.

\subsection{Bridge between official statistics and academia}

Collaboration between official statistics and academia is considered very desirable because of reciprocal knowledge transfer: academia can work on theoretical advances and conduct research without burdening the statistical production process, while official statistics provides a test of feasibility and practical relevance. Attracting more research to topics of official statistics also means developing official statistics as a scientific field of study. The role of EMOS is much more essential and intensive in this respect: university courses can typically afford to dedicate more time to theoretical underpinnings and general frameworks, thus preparing students to look beyond the task at hand; university courses can offer a more extensive involvement of experts from official statistics; representatives of academia and official statistics collaborate on several activities - courses (including webinars), internships and master's theses. The collaboration is the most intensive (and can also be considered as best practice) when the same person is active on both sides, being part-time professor and part-time employed in official statistics. But also other forms of interaction create situations that can trigger learning mechanisms and lead to collaborative learning (see [12]).

\subsection{Bridges towards students}

As any other employer, providers of official statistics have to replace retiring workforce and attract people with new KSAOs. EMOS addresses the need for a recruitment pool of highly educated professionals for purposes of official statistics. Providers of official statistics - including central banks - and universities that work as partners in EMOS, are responsible for building bridges towards students. One bridge that universities and providers of official statistics share is internship, especially if it leads to a master's thesis addressing real problems from official statistics. Such activities present a form of work-based learning that is beneficial for both academia and host organisation because of knowledge co-creation [13].

Although rooted in the traditional educational setting, the pandemic showed us that all topics can also be taught online but they may require a complete overhaul of the teaching method and teaching materials. Not everything is good just because it is delivered online but learning models, modes and methods will never be the same even in more conservative environments. Universities have rapidly adopted digital solutions; some created hybrid learning models, upskilled staff and increased investments in technology but more flexible and active learning approaches are needed to enhance student engagement [14]. We can expect combinations of modern approaches (e.g. blended learning, mobile learning) to maximize the effectiveness of participants' learning experience. This is mainly the task of academia, though in partnership with providers of official statistics, to ensure learning environment that is tailored to the needs of Generation $\mathrm{Z}$ and future staff in official statistics.

\section{Conclusion}

When thinking about all challenges that training of official statistics (and EMOS \& ESTP) is facing, it boils down to the key issue: a low number of students that translates into an even lower number of employees that are more prepared for the world of official statistics than candidates from other backgrounds. For universities, investing in niche programmes and staff is usually not sustainable; for providers of official statistics, initial investment in training novices for the workplace is cumbersome.

Students need a good learning environment and job prospects. Therefore, the division of work to improve this situation is clear: universities have to work on upgrading their learning environment with relevant topics, interesting teaching and efficient learning; providers of official statistics have to work on increasing the appeal of their workplace. So far, experts in statistics have been the predominant profile behind EMOS activities because it was important to determine relevant content. Also in the future, these experts will remain essential because they can evaluate the outcomes of EMOS activities and update the EMOS content. However, other complementary profiles are needed to support develop- 
ment of other important aspects, in particular pedagogic profiles to improve the content delivery and profiles for managing human resources.

Looking in the business world, the human resources departments work on an appealing employee value proposition to attract students from Generation $\mathrm{Z}$. If the best practice is a job offering that only mentions EMOS as a benefit, we see lots of room for improvement. Furthermore, the human resources departments would normally propose various ways to also retain these students, e.g. by managing well an intergenerational and increasingly global workforce.

One of the highlights of EMOS is its mandatory and two-month long internship at a provider of official statistics. Already in its current form, internships serve well all involved parties - universities, providers of official statistics and students, but they can also be strengthened. For example, strongly encouraging work on topics during internships that can develop into master's theses. Or, asking providers of official statistics to develop a list of topics for master's theses with academia. Furthermore, internships could also pursue other objectives that are relevant to workplace, for example, intergenerational learning that could be more systematically enhanced by stimulating students' contacts with employees from different generations, and age-related stereotypes could be addressed by stimulating the exchange of KSAOs between students and employees. Other practices of collaboration should be exposed and promoted to a larger extent to set a good example for other EMOS programmes.

Even when students come to EMOS but choose a different career path, this still has indirect positive effect on official statistics improving statistical literacy of users and public at large. Official statistics should have its advocates everywhere: in production, among providers and users, including the civil society but production should get talent first.

\section{Disclaimer}

The views and opinions of authors expressed herein do not necessarily state or reflect those of the employing organisations of the authors. Reproduction and translation for non-commercial purposes are authorised, provided the source is acknowledged.

\section{References}

[1] Becker GS. Human Capital: a theoretical and empirical analysis, with special reference to education. $3^{\text {rd }}$ edition. Chicago and London: The University of Chicago Press, 1993.

[2] Weller I. Specific human capital: a matching perspective. In: Nyberg AJ, Moliterno TP. editors. Handbook of Research on Strategic Human Capital Resources. Cheltenham, UK: Edward Elgar, 2019.

[3] Eurostat. European Statistics Code of Practice; 2018. Luxembourg: Publications Office of the European Union. Available from: https//ec.europa.eu/eurostat/web/products-catalogues//ks-02-18-142.

[4] Chambers E, Foulon M, Handfield-Jones H, Hankin SM and Michaels EG. III., The War for Talent. The McKinsey Quarterly. 1998; 3: 44-57.

[5] Forbes S, Camden M, Pihama N, Bucknall P, Pfannkuch M. Official statistics and statistical literacy: they need each other. Stat J IAOS. 2011; 27: 113-128.

[6] Townsend M. The national statistical agency as educator. Stat J IAOS. 2011; 27: 129-136.

[7] Reiche BS, Lee Y, Allen DG. Actors, structure, and processes: a review and conceptualization of global work integrating IB and HRM research. Journal of Management. 2019; 45(2): 359383. doi: 10.1177/0149206318808885.

[8] Hinds P, Liu L, Lyon J. Putting the Global in Global Work: An Intercultural Lens on the Practice of Cross-National Collaboration. ANNALS. 2011; 5: 135-188. doi: 10.5465/19416520. 2011.586108.

[9] Earley PC. Redefining interactions across cultures and organizations: Moving forward with cultural intelligence. Research in Organizational Behavior. 2002; 24: 271-299. doi: 10.1016/ S0191-3085(02)24008-3.

[10] Ng ES, Parry E. Multigenerational research in human resource management, Research in Personnel and Human Resources Management (Research in Personnel and Human Resources Management, Vol. 34), Bingley: Emerald Group Publishing Limited. 2016, pp. 1-41. doi: 10.1108/S0742-73012016000003 4008 .

[11] Turner A, Generation Z. Technology and Social Interest. The Journal of Individual Psychology. 2015; 71(2): 103-113.

[12] Dillenbourg P. What do you mean by collaborative learning. In P. Dillenbourg. editor. Collaborative-learning: Cognitive and Computational Approaches. Oxford: Elsevier, 1999, pp. 1-19.

[13] Jakubik M. Enhancing human capital beyond university boundaries, Higher Education. Skills and Work-Based Learning. 2020; 10(2): 434-446. doi: 10.1108/HESWBL-06-2019-0074.

[14] The Economist Intelligence Unit. Bridging the digital divide to engage students in higher education. 2020; Available from: https://eiuperspectives.economist.com/sites/default/files/eiu_ microsoft_higher_education_report.pdf. 